\title{
Health Hazards among Coastal Villagers of Pakistan Due to Arsenic Contaminated Drinking Water
}

\author{
Syed Sanwer Ali ${ }^{{ }^{*}}$, Nasim Karim ${ }^{2}$, Alia Bano Munshi ${ }^{3}$, Ishratullah Siddqui ${ }^{3}$, Farooq A. Khan ${ }^{3}$ \\ ${ }^{1}$ Department of Community Health Sciences, Hamdard College of Medicine \& Dentistry (HCM\&D), \\ Hamdard University, Karachi, Pakistan \\ ${ }^{2}$ Bahria University Medical \& Dental College (BUMDC), Karachi, Pakistan \\ ${ }^{3}$ Center for Environmental Studies, PCSIR Labs. Complex, Karachi, Pakistan \\ Email: ${ }^{*}$ dr_ssan@yahoo.com, nsm_karim@yahoo.com, pcsirklc_ces@hotmail.com
}

Received May 12, 2013; revised June 16, 2013; accepted July 11, 2013

Copyright (C) 2013 Syed Sanwer Ali et al. This is an open access article distributed under the Creative Commons Attribution License, which permits unrestricted use, distribution, and reproduction in any medium, provided the original work is properly cited.

\begin{abstract}
Water supply has become insufficient for the rapidly rising population in Pakistan. As in other parts of Pakistan, coastal villagers also become helpless to use ground water for drinking and daily consumption, due to their need and their not knowing about the quality of water. A number of patients arrived to Karachi hospitals, suffering from a strange disease and this study has been done to find the exact cause of this disease by assuming that arsenic contaminated drinking water may be one of the possibilities. Maximum permissible limit (MRL) of arsenic in drinking water of Pakistan has been calculated by analysis of 50 samples of supply water as $0.05 \mathrm{mg} / \mathrm{l}$. It was observed that most of the residents of Ibrahim Hyderi, Rehri, Chashma, Mubarak, Fagheer Muhammad and Gul Hasan Goths (villages) of the coastal belt of the Karachi city were suffering from melanosis, leuco-melanosis, keratosis, hyperkeratosis, dorsum, non-pitting oedema, gangrene and skin cancer that might be due to arsenic contamination in drinking water. Studied subjects were seriously affected due to paralyzing lower limbs, arms and other body parts in the coastal belt of Karachi, which was observed to be the most prominent health hazards of arsenic. The majority of victims were children. This community problem demands proper addressing and extensive research for improving the quality of life of these villagers.
\end{abstract}

Keywords: Coastal Villages; Pakistan; Ground Water; Arsenic Contamination; Arsenic in Urine; Nails; Hair; Skin

\section{Introduction}

The poor quality of water, especially of which is commonly consumed, has major socioeconomic consequences for Pakistan. The high pollution level of rivers and groundwater has led to different environmental consequences such as reduction of biodiversity, increase in water related diseases, and decrease in agricultural productivity. In addition, mismanagement of water resources has strong socioeconomic repercussions, especially on food security and health [1].

Arsenic, a naturally occurring mineral found in soil and bedrock, is naturally occurring in drinking water supply of Pakistan. Human beings are exposed to arsenic in many different ways such as by ingestion of contaminated water and food; by ingestion of arsenic containing medicinal preparations; by homicidal and suicidal ingestion of arsenic compounds; by inhalation etc., but Arse-

${ }^{*}$ Corresponding author. nic in food or water does not evaporate into the air. The level of arsenic allowed in drinking water has been set at $0.01 \mathrm{mg} / \mathrm{l}$ by the World Health Organization [2]. However, the burning arsenic-containing materials, such as treated lumber, will put arsenic fumes into the air. Burning treated wood in a wood stove or fireplace may expose people to dangerous levels of arsenic. Tobacco smoke contains traces of arsenic [3].

Natural sources of arsenic in water have been attributed to several natural geochemical processes, including oxidation of arsenic-bearing sulfides, de-sorption of arsenic from (hydro) oxides (e.g., iron, aluminum and manganese oxides), reductive dissolution of arsenic bearing iron (hydro) oxides, release of arsenic from geothermal water, and evaporative concentration, as well as leaching of arsenic from sulfides by carbonates [4]. Alarming levels of ground water arsenic concentration have been observed during the course of water quality surveys, conducted by PCRWR during 2001, 2003 and 2004 [5]. The 
presence of arsenic national contamination has been recognized and consequently an arsenic mitigation program, at being level, has already been launched by the government of Pakistan with the assistance of UNICEF [6].

A significant proportion of groundwater in south Asia is contaminated with arsenic. Pakistan has low levels of arsenic in groundwater compared with China, Bangladesh and India. Chronic Arsenic Poisoning can result from chronic exposure to high levels of Arsenic (As) in the air, food or water. However, most cases result from consuming water with toxic levels of Arsenic. Arsenic toxicity has an impact on the entire body but some clinical features are pathognomonic, e.g. skin hyper pigmentation and classical hyperkeratosis of palms and soles. Clinical features of chronic Arsenicosis are highly variable and depend on the levels and duration of arsenic exposure as well as upon the degree of host susceptibility. We have described two cases in a family from Sukkur comprising of nine family members in whom Arsenic toxicity was confirmed by the presence of markedly elevated Arsenic content in their hair and nail samples. Worldwide reported arsenic concentrations in natural water vary from $0.00002 \mathrm{mg} / \mathrm{l}$ to greater than $5 \mathrm{mg} / \mathrm{l}$ [7]. The total arsenic, inorganic and organic forms, in water and spoturine samples, were determined by atomic absorption spectrophotometry (AAS). Cumulative arsenic exposure (dose) was calculated from levels of arsenic in water and duration of use of current drinking water source. Geographically, more arsenic-contaminated groundwater and diseases were alongside coastline, which suggests a strong link between arsenic contamination of groundwater with proximity to Arabian Sea. This is the first reported epidemiological and clinical evidence of arsenic health hazards due to groundwater in coastal villages of Pakistan. Further investigations and focal mitigation measures for arsenic may be carried out in future.

It was also observed that the actual toxicity of arsenic in coastal population varies with general health condition and meals composition along with drinking water storage tanks either underground or overhead tanks as well their diet. Since arsenic is a cumulative substance, the arsenic level has been determined in urine, hair, fingernails/toenails and skin through which Arsenic slowly passes out of the body. In Pakistan, most of the recognized stages of arsenic poisoning have been identified. The risk of arsenic poisoning in Pakistan is increasing.

Three union councils of Karachi namely Rehri, Ibrahim Hyderi and Landhi have over 5000 children with different kinds of disability, including blindness, physical, mental and speech impairment caused by abject poverty, malnutrition, consumption of contaminated water, pollution and unhygienic conditions [8].

Thus millions of people living in the coastal villages of
Pakistan are exposed to arsenic by consuming arseniccontaminated groundwater. The existing literature has revealed the adverse health impact of chronic arsenic poisoning. However, there is little information regarding the role of inequality and inequity on occurrence of chronic arsenicosis and its consequences, which are thought to be very important in policy formulation and its effective implementation. The present study explores the role of social-cultural factors and present development paradigm on the occurrence of the water-born diseases particularly with reference to arsenic contaminated drinking water and its physical and social consequences in the form of disability and handicap, which is becoming a serious problem in Pakistani villages along the coastline of Karachi.

\section{Regional Condition of the Study Area}

The selected villages were Ibrahim Hyderi, Rahri, Chashma, Mubarak, Fagheer Muhammad and Gul Hasan Goths along the coastline of Karachi. Rehri Goth is a coastal fishing village in Pakistan with a population of around 60,000 residents. Most of the people are fisherman and farmers. Mubarak Village, a scenic locality, situated at the Sindh-Balochistan coastal border (Figure 1). Arsenic level in water as a main source of exposure was determined for coastline villages in Karachi. More than three years ago a national campaign to test ground and surface contamination level for toxic metals was conducted. Many households therefore get their water for drinking and cooking from ground water by boring or well due to shortage of supply water.

\section{Methods}

A cross-sectional survey was conducted in 6 arsenic-affected villages, and the population exhibiting arsenical dermatologic manifestation was taken as cases. In addition to researching effects at the individual level, indepth analysis regarding the role of social security, governance, and development policy (water agriculture,

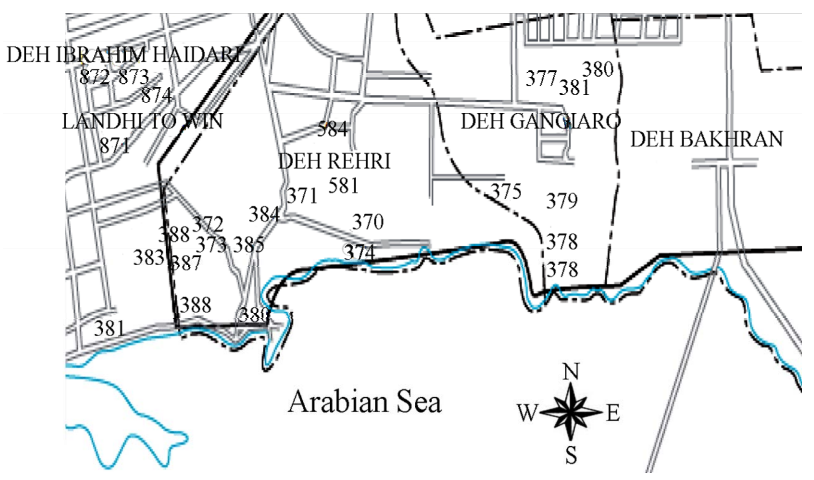

Figure 1. Map of villages location along the coastline of Karachi. 
health care) on arsenic exposure and people's suffering was also conducted. The World Health Organization's International Classification of Impairment, Disability and Handicap (ICIDH) were used, as the guideline tool to define the consequences of disease.

\subsection{Sample Collection}

Water samples were collected from a number of marked sources of water to houses of six villages known as Ibrahim Hyderi, Rahri, Chashma, Mubarak, Fagheer Muhammad and Gul Hasan Goth along the coastline of Karachi. These sources included boring water, self constructed underground water and also supply water by pipes. Samples were collected in one liter polyethylene screw capped bottles, pre-cleaned with detergent, washed with plenty of tap water, soaked in $1 \% \mathrm{HNO}_{3}$ for 24 hrs and finally rinsed with de-ionized water by avoiding any contamination during sampling. After cleaning operation, blanks for bottle selected at random, were prepared in de-ionized water having $1 \%$ analytical grade $\mathrm{HNO}_{3}$ and were analyzed for As. Bottles having detectable level of arsenic were rejected. Sample bottles were then dried at $105^{\circ} \mathrm{C}$ for one hour, recapped and labeled at room temperature, $10 \mathrm{ml}$ nitric acid $\left(\mathrm{HNO}_{3}\right)$ was added to the samples which were used for the estimation of arsenic. Groundwater samples sixty were collected from ten locations of 06 coastal villages in triplicates and were brought to the laboratory and immediately stored at $4^{\circ} \mathrm{C}$ and analyzed as soon as possible. All necessary precautions were observed while sampling, and also during their transportation and storage [9].

\subsection{Analytical Procedure}

A.R grade chemicals were used in the preparation of reagents and standards. Physicochemical analysis was performed for each sample in triplicate and the average values were recorded. $\mathrm{pH}$, TDS and electrical conductance were measured immediately, after collection of samples, using portable digital $\mathrm{pH}$ Meter and conductivity/TDS meter (JENWAY /E.U/430 pH/cad./portable/02162). All other analytical estimations were performed within 48 hours of sampling.

For the analysis of arsenic, reference standards were prepared from Merck AAS standards (1000 ppm). Analyses were performed on a Hitachi Z-5000 Spectrophotometer with Zeeman background correction, equipped with graphite furnace, ZAA software for electronic processing of the results, was used. Determinations of arsenic were done by hydride formation system. Ing/street/district/province/state, etc.).

In the determination of arsenic, for the acid channel $1.2 \mathrm{~N} \mathrm{HCl}$ and for the reducing channel $\mathrm{NaBH}_{4}(1 \%)$ in $\mathrm{NaOH}(0.4 \%)$ was used. The samples were treated with
$20 \% \mathrm{KI}$ in order to reduce all the arsenic "V" to arsenic "III". Blank and samples were also treated in the same manner. Analysis of each metal was carried out in triplicate to get representative results. Indirect measure of the accuracy was obtained from recovery studies on ten water samples spiked with each metal. Recoveries for the spiked samples were $100 \pm 6 \%$.

\section{Results}

\subsection{Facts about Drinking Water}

The principal source of drinking water for the majority in Pakistan is groundwater. Most of the rural areas and many major cities rely on it, although some cities such as Islamabad, Karachi, Hyderabad etc., get water from a number of other sources [10]. In addition to municipal and industrial effluents, contamination of groundwater by arsenic is also becoming a serious problem. In Sindh and the Punjab, approximately $36 \%$ of the population is exposed to a level of contamination higher than $10 \mathrm{ppb}$ and $16 \%$ is exposed to contamination of $50 \mathrm{ppb}$ [1].

Table 1 summarizes the selective physico-chemical analysis of ground water samples, collected from Ibrahim Hyderi, Rahri, Chashma, Mubarak, Fagheer Muhammad and Gul Hasan Goth along the coastline of Karachi and analyzed in order to have an idea about the quality of water. Demographic map indicating arsenic affected areas and level of contamination (Figure 1). The results indicate that most of the samples do not meet the WHO maximum permissible limits of drinking water with reference to TDS and thereby, deteriorating the ground water quality. Almost $76 \%$ samples were found to be effected due to the presence of high dissolved contents ranging from 3000 to $12,200 \mathrm{ppm}$ due to high salinity in this region.

$\mathrm{pH}$ of the samples analyzed, ranges from 7.0 - 8.6 indicating the narrow variations and most of the water samples were weakly alkaline. Since all villages are near to ocean thus highly saline underground water could be expected. It was noticed in all coastal villages that highly saline water was used only for washing floor and so on but not for drinking due to the undesirable saline taste of water. Many villagers fetch water for drinking purpose from far flung places, where water is of bit better quality or depends upon the supply water [11].

There is very little separation of municipal wastewater from industrial effluent in Pakistan. Both flow directly into open drains, which then flow into nearby natural water bodies. There is no regular monitoring program to assess the water quality of the surface and groundwater bodies. There is no surface water quality standard or drinking water quality standard in Pakistan. A comparison of the quality of surface water with the effluent discharge standard clearly demonstrates the extent of pollu- 
Table 1. Sampling physical properties arsenic level in groundwater sample of coastal villages in Karachi.

\begin{tabular}{|c|c|c|c|c|c|c|}
\hline $\begin{array}{l}\text { S. } \\
\text { No }\end{array}$ & Location & $\begin{array}{l}\text { No. of } \\
\text { Sample }\end{array}$ & $\mathbf{p H}$ & $\begin{array}{l}\text { TDS } \\
\text { ppm }\end{array}$ & $\begin{array}{l}\text { Conductance } \\
\mathrm{mS} / \mathrm{cm}\end{array}$ & $\begin{array}{c}\text { Arsenic } \\
\text { ppb }\end{array}$ \\
\hline 1) & Ibrahim Hyderi & 12 & 7.0 & 2150 & 4.35 & 8.00 \\
\hline 2) & Rahri & 10 & 8.1 & 1008 & 2.02 & 3.04 \\
\hline 3) & Chashma Goth & 10 & 7.9 & 680 & 1.38 & 6.56 \\
\hline 4) & Mubark Goth & 10 & 8.1 & 1442 & 2.86 & 5.56 \\
\hline 5) & $\begin{array}{l}\text { Fagheer } \\
\text { Muhammad } \\
\text { Goth }\end{array}$ & 10 & 8.2 & 2616 & 4.65 & $\mathrm{BDL}^{*}$ \\
\hline 6) & Gul Hasan Goth & 8 & 8.6 & 4192 & 7.34 & 5.36 \\
\hline
\end{tabular}

BDL: Below detection limit (As 0.15 ppb); Note: Mean Values are presented.

tion in the water bodies due to the discharge of industrial and municipal effluent. It is a fact that a number of factors need to be highlighted and addressed in order to improve, protect and maintain the quality of freshwater resources of the Pakistan.

This survey initiated in 2002 was showed that $>80 \%$ of the water sources were untested and were use in since years and years (Figure 2).

High levels of Arsenic in the subsoil water has been reported from all over the world and globally many areas with high As content have been identified by the WHO 1993. These include areas surrounding coastline as well and $<10 \%$ of the untested water samples had low level of As and remaining samples contained higher concentration of As than permissible concentration.

The summary of the results shown is that drinking water samples, collected from coastal villages have been found to be safe with respect to arsenic except three samples collected from Ibrahim Hyderi and Chashma Goth (Table 1).

WHO has proposed two norms, namely highest desirable and maximum permissible, based on which three levels have been defined (Table 2).

All international standards of drinking water norms with respect to As $[12,13]$ are varied and the comparative standards of Pakistan is given in Table 3.

\subsection{Impacts of Arsenic Contaminated Drinking Water}

It is also important to note that although groundwater is still the primary source of drinking water supplies, it is estimated that 40 million residents depend on irrigation water for their domestic use, especially in areas where the groundwater is brackish like coastal villages. The associated health risks are grave, as bacteriological contamination of irrigation water often exceeds WHO limits
Table 2. Maximum contamination Arsenic level in drinking water as per international record*.

\begin{tabular}{|c|c|c|c|c|}
\hline $\begin{array}{c}\text { US EPA } \\
\text { maximum } \\
\text { contamination } \\
\text { level (ppm) }\end{array}$ & $\begin{array}{c}\text { CDWQ }^{\mathbf{b}} \\
\text { maxium } \\
\text { acceptable } \\
\text { concentration } \\
(\mathrm{ppm})\end{array}$ & $\begin{array}{c}\text { EEC } \\
\text { maximum } \\
\text { admissible } \\
\text { concentration } \\
\text { PPM }\end{array}$ & $\begin{array}{c}\text { Japan } \\
\text { maximum } \\
\text { admissible } \\
\text { concentration } \\
(p p m)\end{array}$ & WHO \\
\hline 0.01 & 0.01 & 0.05 & 0.01 & 0.01 \\
\hline \multicolumn{5}{|c|}{ WHO (1971) guidline } \\
\hline $\begin{array}{c}\text { Highest } \\
\text { desirable limit } \\
\text { (HDL) (ppm) }\end{array}$ & $\begin{array}{c}\text { Maximum } \\
\text { permissible } \\
\text { limit (MPL) } \\
(\mathrm{ppm})\end{array}$ & HDL < S (\%) & $\begin{array}{c}\text { Alert } \\
\text { HDL-A (\%) } \\
\text {-MPL }\end{array}$ & $>$ MPL \\
\hline 0.01 & 0.05 & 94.00 & 6.06 & 0 \\
\hline
\end{tabular}

"HACH (2003). USEPA—United State Protection Agency Canadian Drinking water quality guideline European Economic World Health organization.

Table 3. Comparative standard of arsenic in drinking water.

\begin{tabular}{ccc}
\hline S. No & Authorities & Maximum permissible limits (ppb) \\
\hline 1$)$ & WHO & 10 \\
$2)$ & PSQCA & 10 \\
$3)$ & BI & 50 \\
$4)$ & US-EPA & 10 \\
$5)$ & Indian Standard & 50 \\
\hline
\end{tabular}

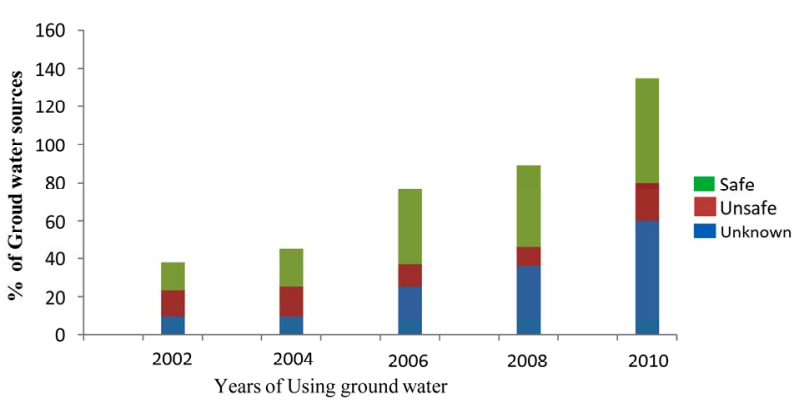

Figure 2. Sources of water samples collection showing contamination of Arsenic.

even for irrigation. The poor quality of drinking water has major socioeconomic consequences for Pakistan [10].

Any parameter below highest desirable levels is marked as "Safe", between highest desirable and maximum permissible levels as "Alert" and above permissible level marked as "Toxic". Based on this criterion, all the drinking water samples of ground water of coastal villages collected in the study have been categorized as safe, alert or toxic with respect to each of the parameters mentioned in Table 4.

The summary of the results shown is that drinking water samples, collected from coastal villages have been 
Table 4. Summary of safe (S) Alert (A) and Toxic (T) according to WHO guideline.

\begin{tabular}{|c|c|c|c|c|}
\hline \multicolumn{2}{|c|}{ WHO Guideline* } & \multirow{2}{*}{$\begin{array}{c}\text { S (\%) } \\
\text { Below } \\
\text { HPL }\end{array}$} & \multirow{2}{*}{$\begin{array}{c}\text { A (\%) B/W } \\
\text { HDL and } \\
\text { MPL }\end{array}$} & \multirow{2}{*}{$\begin{array}{c}\text { T (\%) } \\
\text { Above } \\
\text { MPL }\end{array}$} \\
\hline $\begin{array}{c}\text { Highest } \\
\text { Desirable Limit } \\
\text { ppm (HPL) }\end{array}$ & $\begin{array}{l}\text { Maximum } \\
\text { Permissible Limit } \\
\text { ppm (MPL) }\end{array}$ & & & \\
\hline 0.01 & 0.05 & 93.94 & 6.06 & 0 \\
\hline
\end{tabular}

*WHO (1971).

found to be safe with respect to arsenic except three samples collected from Ibrahim Hyderi and Chashma Goth, that falls under the Alert range as per existing scale of WHO [13]. These observations are of concern; as arsenic concentration in ground water is prove to sharp fluctuation depending upon geochemical conditions. Data has been evaluated statistically and given in Table 5 .

Authors suggest periodic monitoring of water samples of these locations to detect any possible outbreak of arsenic at the onset. It may further be seen that all water samples have arsenic concentration within the maximum permissible limits as regards existing drinking water guidelines except Japanese standard.

To look into the trend and distribution pattern of arsenic occurrence analytical data was subjected to several statistical treatments and a conventional descriptive statistics based on normal distribution has been shown in Table 5.

Arsenic was analyzed in the collected samples in the range of 0.16 to $8.0 \mathrm{ppb}$. Small differences between the mean and median in each case and high standard deviation indicate that the distribution is asymmetric. Wide range of data indicates the presence of extreme values, which are likely to bias the normal distribution statistics. Occurrence of arsenic is very sporadic and marked difference in its concentration occurs at very short distance. The geochemical setup of ground water of coastal villages suggests, that the natural source of arsenic in groundwater is the arsenic bearing mineral associated with sandy, rocky and muddy basement of coastline [14].

Table 1, arsenic levels are exceeding the WHO guideline value for drinking water of $0.01 \mathrm{mg} / \mathrm{l}$. The available data indicate that arsenic contamination in some areas is not far above the drinking water standard of $0.05 \mathrm{mg} / \mathrm{l}$, but on the other hand, at least some of the groundwater samples do not exceed the WHO guideline (Figure 3). This indicates that the arsenic contamination of the groundwater is not present everywhere but rather that the elevated arsenic levels occur locally, probably influenced by the local hydrogeological situation and human activities.

Our data showed that modern agriculture practice and drinking water policy has made people more dependent on groundwater and hence more exposure to arsenic.
Table 5. Normal distribution Statistics for Arsenic in the Ground Water of coastal villages*.

\begin{tabular}{cc}
\hline Statistics & As \\
\hline Mean & 2.96 \\
Median & 1.31 \\
Standard Deviation & 5.33 \\
Sample Variance & 28.45 \\
Minimum & 0.16 \\
Maximum & 29.88 \\
Mode & 1.04 \\
\hline
\end{tabular}

*Only those water samples have been considered for statistical treatment in which the metals analyzed were found to be within detection limits.

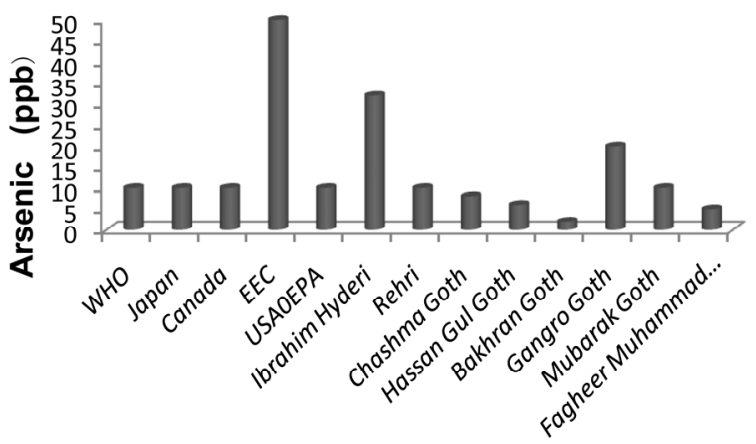

Figure 3. Arsenic level in coastal villages in comparison of world standards.

Occurrence and severity of manifestation was significantly associated $(P<0.05)$ with arsenic exposure level, gender, occupation, socioeconomic status, nutrition, and access to health care. The poor population suffered more due to malnutrition, occupation, access to healthcare services as well as social services, and economic constraint, thereby impacting their ability to seek safer and alternative sources of water.

\subsection{Health Problems}

Elevated exposure to inorganic arsenic (As) is associated with cancers of the skin, bladder, and lung [15], reproductive and developmental effects [16], cardiovascular disease [17], and skin lesions [18]. The fact that chronic arsenic toxicity can result in serious morbidity and mortality, including malignancies of skin and internal organs, we suggest that the issue of toxic levels of As in sub-soil water used for human consumption should be addressed on a priority basis [19]. (Among the affected people, the most common observed cases showed paralysis of the lower limbs, arms and other body parts, melanosis, keratosis, hyperkeratosis and dipigmentation (leuco-melanosis). According to available data the Lyari Community Hospital (LCH) identified 1000 patients with arsenical 
[3] S. M. Talebi, M. Abedi and A. Mohammadkhah, "The Relationship between Concentration of Polycyclic Aromatic Hydrocarbons and Heavy Metals Urban Air," Pollution Research, Vol. 24, No. 2, 2005, pp. 451-454.

[4] B. Bennett and M. J. Dudas, "Release of Arsenic and Molybdenum by Reductive Dissolution of Iron Oxides in a Soil with Enriched Levels of Native Arsenic,” Journal of Environmental Engineering \& Sciences, Vol. 2, 2003, pp. 265-272. http://dx.doi.org/10.1139/s03-028

[5] Pakistan Council of Research in Water Resources (PCRWR), "Alarming Levels of Groundwater Arsenic Concentration Has Been Observed during the Course of Water Quality Surveys Conducted by PCRWR during 2001, 2003 and 2004."

[6] A. S. Malik, "UNICEF-Pakistan Taking Clean Water and Hygiene Awareness to Rural Pakistan,” 2013.

[7] A. L. Smith, P. A. Lopipero, M. N. Bates and C. M. Steinmaus, "Arsenic Epidemiology and Drinking Water Standards,” Science, Vol. 296, No. 5576, 2002, pp. 2145-2146. http://dx.doi.org/10.1126/science.1072896

[8] WHO, "Prevention. Cancer Control: Knowledge into Action: WHO Guide for Effective Programs; Module 2,” WHO Press, Geneva, 2007.

[9] WHO, “Guidelines for Drinking Water Quality,” Vol. 1, 2nd Edition, World Health Organization, Geneva, 1993.

[10] Pak-SCEA, "Pakistan; Strategic Country Environmental Assessment Report: Rising to the Challenges,” 2006.

[11] R. T. Nickson, J. M. McArthur, B. Shrestha, T. O. KyawMyint and D. Lowry, “Arsenic and Other Drinking Water Quality Issues, Muzaffargath Pakistan,” Journal of Applied Geochemistry, Vol. 20, 2005, p. 55.

[12] HACH DR/4000 1997-2003, "Spectropho Tometer Procedures Manual. (C) HachCompany, USA,”

[13] WHO, "Guidelines for Drinking Water Quality," 4th Edition, 2011.

[14] J. H. Gulledge and O. J. T. Connor, "Removal of Arsenic (V) from Water by Adsorption on Aluminum and Ferric Hydroxide," Journal of American Water Works Association, Vol. 65, No. 8, 1973, pp. 548-552.

[15] G. Marshall, C. Ferreccio, Y. Yuan, M. N. Bates, C. Stein- maus and S. Selvin, "Fifty-Year Study of Lung and Bladder Cancer Mortality in Chile Related to Arsenic in Drinking Water,” Journal of the National Cancer Institute, Vol. 99, No. 12, 2007, pp. 920-928. http://dx.doi.org/10.1093/jnci/djm004

[16] G. A. Wasserman, M. X. Liu, F. Parvez, P. Factor-Litvak, H. Ahsan and D. Levy, "Arsenic and Manganese Exposure and Children's Intellectual Function,” Neurotoxicology, Vol. 32, No. 4, 2006, pp. 450-457.

[17] Y. Chen, A. van Geen, J. H. Graziano, A. Pfaff, M. Madajewicz and F. Parvez, "Reduction in Urinary Arsenic Levels in Response to Arsenic Mitigation Efforts in Araihazar, Bangladesh,” Environmental Health Perspectives, Vol. 115, No. 6, 2007, pp. 917-923. http://dx.doi.org/10.1289/ehp.9833

[18] H. Ahsan, Y. Chen, F. Parvez, L. Zablotska, M. Argos and I. Hussain, "Arsenic Exposure from Drinking Water and Risk of Premalignant Skin Lesions in Bangladesh: Baseline Results from the Health Effects of Arsenic Longitudinal Study," American Journal of Epidemiology, Vol. 163, No. 12, 2006, pp. 1138-1148. http://dx.doi.org/10.1093/aje/kwj154

[19] T. G. Kazi, M. B. Arain, J. A. Baig, M. K. Jamali, H. I. Afridi, N. Jalbani, R. A. Sarfraz, A. Q. Shah and A. Niaz, "The Correlation of Arsenic Levels in Drinking Water with the Biological Samples of Skin Disorders. Science of the Total Environment,” 2009.

[20] T. Ahsan, K. Zehra, A. Munshi and S. Ahsan, "Chronic Arsenic Poisoning," Journal of Pakistan Medical Association, Vol. 59, No. 2, 2009, pp. 105-107.

[21] Y. Chen, J. H. Graziano, F. Parvez, M. Liu, V. Slavkovich and T. Kalra, "Arsenic Exposure from Drinking Water and Mortality from Cardiovascular Disease in Bangladesh: Prospective Cohort Study,” British Medical Journal, Vol. 362, 2011, p. d2431.

[22] G. D. N. Mazumdar, D. J. Gupta and A. Santra, “Non-Cancer Effects of Chronic Arsenicosis with Special Reference to Liver Damage,” In: C. O. Abernathy, R. L. Calderon and W. R. Chappell, Eds., Arsenic: Exposure and Health Effects, Chapman \& Hall, London, 1997, pp. 112-123. http://dx.doi.org/10.1007/978-94-011-5864-0_10 